The p53 Tumor Suppressor Pathway and Cancer 


\section{PROTEIN REVIEWS}

Editorial Board:

EDITOR-IN-CHIEF: $\quad$ M. ZOUHAIR ATASSI, Baylor College of Medicine, Houston, Texas

EDITORIAL BOARD: LAWRENCE J. BERLINER, University of Denver, Denver, Colorado

ROWEN JUI-YOA CHANG, University of Texas at Houston, Houston, Texas

HANS JÖRNVALL, Karolinska Institutet, Stockholm, Sweden GEORGE L. KENYON, University of Michigan, Ann Arbor, Michigan

BRIGITTE WITTMAN-LIEBOLD, Wittman Institute of Technology and Analysis, Tetlow, Germany

Recent Volumes in this Series

VIRAL MEMBRANE PROTEINS: STRUCTURE, FUNCTION, AND DRUG DESIGN

Edited by Wolfgang B. Fischer

THE p53 TUMOR SUPPRESSOR PATHWAY AND CANCER

Edited by Gerard P. Zambetti

PROTEOMICS AND PROTEIN-PROTEIN INTERACTIONS: BIOLOGY, CHEMISTRY, BIOINFORMATICS, AND DRUG DESIGN

Edited by Gabriel Waksman

A Continuation Order Plan is available for this series. A continuation order will bring delivery of each new volume immediately upon publication. Volumes are billed only upon actual shipment. For further information please contact the publisher. 


\section{The p53 Tumor Suppressor Pathway and Cancer}

Edited by

Gerard P. Zambetti

St. Jude Children's Research Hospital

Memphis, Tennessee

黛 Springer 
Library of Congress Cataloging-in-Publication Data

Zambetti, Gerard P.

The p53 tumor suppressor pathway and cancer/Gerard P. Zambetti.

p. $\quad \mathrm{cm}$. (Protein reviews)

Includes bibliographical references and index.

ISBN 0-387-24135-3

1. p53 antioncogene. 2. p53 protein. I. Title. II. Series.

RC268.44.P16Z35 2005

$616.99^{\prime} 4042-\mathrm{dc} 22$

A C.I.P. Catalogue record for this book is available from the Library of Congress.

ISBN-10: 0-387-24135-3

ISBN-13: 978-0387-24135-7

(C) 2005 Springer Science Business Media, Inc.

All rights reserved. This work may not be translated or copied in whole or in part without the written permission of the publisher (Springer Science+Business Media, Inc., 233 Spring Street, New York, NY 10013 , USA), except for brief excerpts in connection with reviews or scholarly analysis. Use in connection with any form of information storage and retrieval, electronic adaptation, computer software, or by similar or dissimilar methodology now known or hereafter developed is forbidden. The use in this publication of trade names, trademarks, service marks and similar terms, even if they are not identified as such, is not to be taken as an expression of opinion as to whether or not they are subject to proprietary rights.

Printed in Singapore (BS/DH)

987654321

springeronline.com 


\section{Preface}

The current year (2004) marks the Silver Anniversary of the discovery of the p53 tumor suppressor. The emerging field first considered p53 as a viral antigen and then as an oncogene that cooperates with activated ras in transforming primary cells in culture. Fueling the concept of p53 acting as a transforming factor, p53 expression was markedly elevated in various transformed and tumorigenic cell lines when compared to normal cells. In a simple twist of fate, most of the studies conducted in those early years inadvertently relied on a point mutant of $\mathrm{p} 53$ that had been cloned from a normal mouse genomic library. A bona fide wild-type p53 cDNA was subsequently isolated, ironically, from a mouse teratocarcinoma cell line. A decade after its discovery, p53 was shown to be a tumor suppressor that protects against cancer. It is now recognized that approximately half of all human tumors arise due to mutations within the p53 gene. As remarkable as this number may seem, it significantly underrepresents how often the p53 pathway is targeted during tumorigenesis. It is my personal view, as well as many in the p53 field, that the p53-signaling pathway is corrupted in nearly $100 \%$ of tumors. If you are interested in understanding cancer and how it develops, you must begin by studying $\mathrm{p} 53$ and its pathway.

After demonstrating that $\mathrm{p} 53$ functions as a tumor suppressor the field exploded and p53 became a major focus of scientists around the world. Indeed, there were approximately 300 published studies on $\mathrm{p} 53$ by 1990 and at last count there are more than 30,000 publications. The amount of information on p53 is truly overwhelming and in a real sense has created subspecialties within the field. It is quite difficult, if not impossible, to be well versed and up-to-date on all aspects of p53. It is for this reason that we have decided to consolidate the most important, landmark findings in one place, hence the purpose of writing this book.

The thought behind putting this book together was to assemble a group of outstanding scientist who significantly contributed to our understanding of how p53 functions in tumor suppression. By all means this book does not cover all aspects of $\mathrm{p} 53$; rather, it is meant to provide the necessary information to bring a novice up to speed with the field. This is no small feat as approximately 1,000 manuscripts have 
been published on p53 within just the first three months of this year and there are no signs of this pace letting up (ISI Web of Knowledge).

The book has been structured to first provide an overview and a historical perspective into how the p53 field became what it is today and where it may be heading, as conveyed by Dr. Arnold Levine, the codiscoverer of p53 (Chapter 1). Much has been learned about how p53 functions from its molecular structure and Dr. Thanos Halazonetis has reviewed the latest NMR and crystallography data (Chapter 2). Within this chapter it is important to note that the mutations observed in human cancer do not happen randomly and that many of these occur at the sites where p53 contacts DNA or at critical junctures that disrupt DNA binding. The studies on p53 binding to DNA leads to the chapters on how p53 functions as a tumor suppressor by regulating gene expression (Chapters 3 and 4). Clearly p53 recognizes specific DNA sequences and activates a series of downstream target genes. This area is reviewed by Dr. Wafik El-Deiry who identified a p53 DNA binding consensus site and discovered p2 ${ }^{\mathrm{Cip} 1}$ as a p53-regulated gene while working as a postdoctoral fellow in Dr. Bert Vogelstein's lab (see Chapter 3). It is also known that p53 selectively turns off the expression of down stream targets (transrepression), some of which are thought to be required for cell survival. Our current understanding of how p53 suppresses gene expression is extensively reviewed by Dr. Maureen Murphy in Chapter 4. Dr. Murphy moved this area of research from artifact-prone, overexpression assays to the identification of endogenous genes that are downregulated by p53 and are required for cell viability.

In Chapter 5, Drs. Ettore Appella and Carl Anderson summarize our understanding of how p53 becomes activated during cell stress, which occurs almost exclusively by posttranslational modification. The development of site-specific antibodies has been critical for studying p53 activation and Drs. Appella and Anderson lead the field in the generation of these reagents. Site-specific antibodies have been instrumental in determining how phosphorylation and acetylation is regulated and how these modifications control p53 function.

As indicated above, it is the p53-signaling pathway acting as a whole that suppresses tumorigenesis. Obviously, perturbations along the pathway could compromise p53 activity and consequently promote tumor development. In Chapter 6, Dr. Ute Moll summarizes what mutations have been observed in p53, how they can arise, and how the pathway may be corrupted without directly affecting p53 itself. It was Dr. Moll who first observed the mislocalization of wild-type p53 in the cytoplasm of primary breast cancer cells and subsequently in neuroblastoma cells. With p53 residing in the wrong subcellular compartment, it no longer functions efficiently to protect against cancer despite being "normal" and this contributes to tumorigenesis.

A prominent mechanism for regulating p53 levels and activity is the intricate negative feedback loop that exists between p53 and Mdm2, a protein that is known to bind p53 and to block its function in multiple ways. How Mdm2 is regulated and in turn how it negatively regulates p53 is described in excellent detail in Chapter 7 by Dr. Jamil Momand, who identified Mdm2 as a critical p53 interacting protein while working as a postdoctoral fellow in Dr. Levine's lab. Subsequent studies revealed the existence of a highly related protein termed, MdmX. What is known about how 
MdmX is expressed and how it functionally interacts with p53 and Mdm2 is also presented in this chapter. Pay close attention to the elegant genetic studies examining the phenotypes of Mdm2 and MdmX knockout mice and how these responses are influenced by p53 status.

Recent work has uncovered highly related p53 family members, specifically p63 and p73, suggesting that p53 may not act alone in suppressing tumor growth. Drs. Elsa Flores and Tyler Jacks review the literature surrounding the p53 family of proteins and present some of their latest studies on the consequence of p63 and p73 loss on cell growth and survival (Chapter 8). Intuitively, the functional interaction that exists between the family members would suggest an important role for p63 and p73 in tumor suppression. The consequence of deleting p63 and p73 in knockout mice on tumor susceptibility remains to be seen and should be enlightening.

The original observations of p53 acting as an oncogene during the time when most studies were carried out using the mutant form are not incorrect. Clearly, loss of p53 compromises tumor suppressor function as demonstrated by the finding that $100 \%$ of p53-knockout mice develop malignant tumors, usually within several months of age. Nevertheless, most tumors associated with defects in p53 express a fulllength missense p53 protein. It is important to keep in mind that the missense protein is usually expressed at high levels in the nucleus and is not biochemically inert. The consequence that overexpression of mutant p53 has on tumor cell growth and survival is not completely understood. What is recognized however is that mutant p53 has the capability of making matters worse and can actively promote tumorigenesis through a gain-of-function mechanism. In Chapter 9, Drs. Alex Sigal and Varda Rotter discuss what is known about mutant p53 tumor promoting properties. Dr. Rotter is most appropriate to review this area as it was her seminal observations in the 1980s that provided the first insight into the tumorigenic properties of mutant.

Lastly, in Chapter 10, Dr. Andrei Gudkov summarizes the current state of affairs concerning the development of compounds that can restore tumor suppressor function to mutant p53. Considering that half of all human cancers express a mutant form of p53, the identification of a small molecule that could correct the biochemical defect could have a huge clinical impact. Although I was skeptical that this could ever happen, recent work by Wiman and coworkers provide a strong indication that this indeed can be possible. These exciting findings as well as other important studies are reviewed in this chapter. In addition, there are certain circumstances where p53 activation can actually be detrimental, such as during stroke, chemotherapy, or neurological degeneration. Therefore, compounds that inhibit wild-type p53 activity can also be desirable. Dr. Gudkov has been instrumental on this front and has recently identified a compound called pifithrin, which is also discussed here. My intent was to conclude the book with this chapter to provide some hope that there are reasonable ways to combat human cancers and other diseases associated with p53 mutations or perturbations in its pathway.

There is some redundancy between the chapters and this is unavoidable as each "subspecialty" overlaps to a degree with one another. Although these areas do overlap 
on occasion, the personal views, which are spun on the literature as discussed within each chapter, provides a rich and much broader understanding of the topic.

Dr. Arnie Levine once said that science moves forward in waves. He said that uncovering the true function of p53 as a tumor suppressor in 1989 was one such wave and that there would be others. Soon thereafter, Dr. Momand identified Mdm2 as a p53 binding protein. It did not take long to prove that Mdm2 was an oncogene because it blocks p53 function. From this simple observation a subfield was established leading to the demonstration that Mdm2 is frequently amplified and overexpressed in human cancers. What the future holds for p53 and the genes that are tied into this extremely important pathway should bring yet more exciting waves!

Gerard P. Zambetti 


\section{Contents}

1. The p53 Network 1

Arnold J. Levine, Jill Bargonetti, Gareth L. Bond, Josephine Hoh,

Kenan Onel, Michael Overholtzer, Archontoula Stoffel,

Angelica K. Teresky, Christine A. Walsh, and Shengkan Jin

2. The Three-Dimensional Structure of p53

Elena S. Stavridi, Yentram Huyen, Emily A. Sheston, and Thanos D. Halazonetis

3. Transcriptional Activation by p53: Mechanisms and Targeted Genes Timothy MacLachlan and Wafik El-Deiry

4. Transcriptional Repression by the 553 Tumor Suppressor Protein Jack T. Zilfou and Maureen E. Murphy

5. Posttranslational Modifications of p53: Upstream Signaling Pathways

Carl W. Anderson and Ettore Appella

6. p53 in Human Cancer - Somatic and Inherited Mutations and Mutation-independent Mechanisms

Ute M. Moll and Nicole Concin

7. MDM2 and MDMX Regulators of p53 Activity

Jamil Momand, Paul Joseph Aspuria, and Saori Furuta

8. p53 Family Members: $\mathrm{p} 63$ and $\mathrm{p} 73$

Elsa R. Flores and Tyler Jacks 
9. The Oncogenic Activity of p53 Mutants Alex Sigal and Varda Rotter

10. Therapeutic Strategies Based on Pharmacological Modulation of p53 Pathway

Andrei V. Gudkov

Index 